Published in final edited form as:

Environ Toxicol Chem. 2020 July ; 39(7): 1421-1428. doi:10.1002/etc.4732.

\title{
Effect of Agrochemical Exposure on Schistosoma mansoni Cercariae Survival and Activity
}

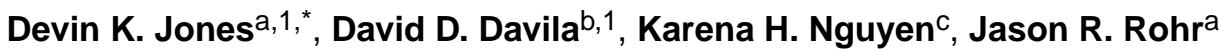 \\ aUniversity of Notre Dame, Department of Biological Sciences, Notre Dame, Indiana, USA \\ ${ }^{b}$ College of Arts and Sciences, University of Miami, Coral Gables, Florida, USA \\ 'Department of Integrative Biology, University of South Florida, Tampa, Florida, USA
}

\begin{abstract}
Singular use of activity assays or staining dyes to assess pathogen agrochemical tolerance can underestimate tolerance if pesticides cause sublethal effects. We exposed Schistosoma mansoni cercariae, the aquatic life stage of this trematode that infects humans, to 4 insecticides at 5 concentrations using a 24-h time-to-death assay. We used Trypan blue dye, which stains dead tissue, and activity assays simultaneously to discriminate dead from live but paralyzed individuals. Whereas cypermethrin, deltamethrin, and dimethoate exposure did not affect cercariae at any ecologically relevant concentrations, methamidophos exposure increased survival of cercariae compared with those in the controls. This was because methamidophos-induced paralysis reduced cercarial activity and thus energy expenditures, extending the lifespan of this short-lived parasite that causes human schistosomiasis. These findings highlight that sublethal effects should be considered when pesticide effects on disease are under investigation.
\end{abstract}

\section{Keywords}

Ecotoxicology; Parasite; Organophosphate; Pyrethroid; Trematode

\section{INTRODUCTION}

The rate of production and use of synthetic chemicals, such as pesticides, has outpaced other human drivers of global environmental change (Bernhardt et al. 2017), which has resulted in the contamination of ecosystems worldwide (Vorosmarty et al. 2010; Stehle and Schulz 2015). Exposure to pesticides can cause direct, lethal effects on sensitive species or sublethal effects on an organism's behavior, physiology, and/or morphology (Fleeger et al. 2003; Relyea and Hoverman 2006; Rohr et al. 2006; Clements and Rohr 2009; Kohler and Triebskorn 2013; Halstead et al. 2014). Organophosphate and pyrethroid insecticides, for example, target important esterases and nerve cell gates leading to ionic imbalances and

\footnotetext{
*Address correspondence to devin.k.jones@gmail.com.

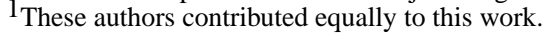

Supplemental Data—The Supplemental Data are available on the Wiley Online Library at https://doi.org/10.1002/etc.4732.

This article includes online-only Supplemental Data.
} 
uncontrollable convulsions and tremors before paralysis and eventual death (Sanchez-Bayo 2012; Antwi and Reddy 2015). Given that pesticide production and trade are estimated to increase drastically by 2050 (Tilman et al. 2001; Rohr et al. 2019), there is a growing need to understand how agrochemical contamination impacts human and wildlife health.

Freshwater ecosystems, which are vital for global economies, societal well-being, and maintaining human health (Baron et al. 2002; Strayer and Dudgeon 2010; Costanza et al. 2014), are threatened by agricultural activities and agrochemical use (Vorosmarty et al. 2010; Malaj et al. 2014; Ippolito et al. 2015). For instance, more than $40 \%$ of the global land area is at risk of producing insecticide runoff to lotic systems (Ippolito et al. 2015). Moreover, agricultural runoff can carry microorganisms including bacterial, viral, fungal, and helminth pathogens into adjacent aquatic environments that can lead to disease outbreaks or modify transmission dynamics of endemic pathogens (Patz et al. 2000, 2004; Rizak and Hrudey 2008). In developing countries, such as those in sub-Saharan Africa, increased land conversion for agriculture (Tilman et al. 2001; Alexandratos and Bruinsma 2012) combined with water management and development for irrigation (Steinmann et al. 2006; Sokolow et al. 2017) has led to an increase in human exposure to agrochemicals and waterborne pathogens (Southgate 1997; Jepson et al. 2014; Lapworth et al. 2017). Understanding the effects of agrochemical contamination on waterborne pathogens is vital because the density of human settlements near managed water systems and the demand for agricultural output are increasing (Lambin et al. 2003; Steinmann et al. 2006; Rohr et al. 2019).

Schistosomiasis is one example of a waterborne, neglected tropical disease that is affected by agriculture (Halstead et al. 2018). Schistosomiasis afflicts more than 200 million people annually, of which over $90 \%$ reside in sub-Saharan Africa, and is caused by aquatic parasitic Schistosoma trematodes (World Health Organization 2010; Fenwick 2012). Freeswimming Schistosoma cercariae are released from intermediate freshwater snail hosts and penetrate the skin of definitive human hosts while in the water. Schistosoma eggs, produced by matured worms, leave the human host via feces or urine, and hatch in aquatic environments where the next free-living stage, miracidia, penetrate the snail intermediate host to complete the life cycle. Cercariae and miracidia are short-lived organisms, generally only having enough reserves to live for approximately $24 \mathrm{~h}$ (Olivier 1966; Purnell 1966). In an outdoor mesocosm experiment, populations of intermediate snail hosts were shown to increase following bottom-up and top-down indirect effects caused by exposure to the herbicide atrazine and the insecticide chlorpyrifos, respectively (Halstead et al. 2018); whereas herbicide exposure increased algal food resources for snails, insecticide exposure reduced snail predator densities. Thus, human infection risk was predicted to increase following pesticide contamination of aquatic systems due to an increase in intermediate host densities. Indeed, Becker et al. (2020) reported increased intermediate snail host densities among sampled areas of Lake Victoria in Kenya characterized by pesticide pollution and eutrophication. However, it remains unknown how pesticide exposure influences the aquatic Schistosoma life stages. As insecticide runoff potential is high in developing African nations where schistosomiasis is prevalent (World Health Organization 2010; Stensgaard et al. 2013; Ippolito et al. 2015), investigating the direct lethal and sublethal effects agrochemical exposure has on the aquatic life stages of Schistosoma is of great importance. 
Schistosoma miracidia and cercariae might be sensitive to environmental contaminants given their occurrence in freshwater environments during the transition between intermediate and definitive hosts (Pietrock and Marcogliese 2003). Surprisingly, previous studies have not reported significant lethal effects of pesticide exposure on either life stage of Schistosoma (Halstead et al. 2018). In contrast, cercariae of trematode species found in North American snails are known to be sensitive to the commonly applied herbicides atrazine (Koprivnikar et al. 2006; Rohr et al. 2008) and glyphosate (Monte et al. 2016), as well as organophosphate, pyrethroid, and neonicotinoid insecticides (Hua et al. 2016). Interestingly, the method of assigning cercarial survival differed among these studies. Survival can be assessed with 1) general swimming or climbing movement (Koprivnikar et al. 2006), 2) movement following stimuli (Reddy et al. 2004; Rohr et al. 2008; Raffel et al. 2009; Hua et al. 2016), or 3) Trypan blue staining (Halstead et al. 2018). Complicating the use of either activity or dyes to examine effects of pesticide exposure is that many insecticides cause paralysis; thus, paralyzed cercariae cannot respond to stimuli but can excrete Trypan blue, which is absorbed by dead cells and excreted by living cells (Strober 2001; McMahon and Rohr 2014). It is possible that pesticide toxicity is then underestimated if paralysis is mistaken for true mortality events (i.e., false positives). Moreover, if exposure to insecticides that target the nervous system reduces activity or causes paralysis, this could reduce energy consumption of short-lived, free-living, aquatic organisms, such as cercariae, potentially extending their lifespan. This could explain some of the variability in cercarial responses to insecticides.

To assess this hypothesis, we exposed Schistosoma mansoni cercariae, the trematode species responsible for intestinal schistosomiasis, to 5 different concentrations of 4 insecticides from 2 different pesticide classes (organophosphate and pyrethroid) using a 24-h time-to-death assay. To reduce potential false positives, we simultaneously employed activity assays and Trypan blue dye to distinguish among live and active, live and paralyzed, and dead cercariae (Supplemental Data, S1 Dataset). We predicted that cercarial exposure to the insecticides would cause paralysis given the need for both acetylcholine esterase (organophosphate target) and voltage-gated ion channel (pyrethroid target) function in Schistosoma cercarial movement (Bruckner and Vage 1974; Salvador-Recatala and Greenberg 2012), thus reducing activity. We also hypothesized that insecticide-induced paralysis would increase cercarial survival compared with cercariae not exposed to insecticides that were actively swimming, consuming limited energetic resources.

\section{MATERIALS AND METHODS}

\section{Pesticide background}

We chose 4 insecticides commonly used and detected in sub-Saharan African countries (Williamson et al. 2008; Jepson et al. 2014; Donald et al. 2016). Dimethoate (CAS 60-51-5; Sigma-Aldrich batch number: BCBS9338, purity: 99.8\%) and methamidophos (CAS 10265-92-6; Sigma-Aldrich batch number: BCBT1513, purity: 99.1\%) are broad-spectrum organophosphate insecticides that are acetylcholinesterase inhibitors used to protect crops such as grapes, tobacco, and potatoes. Deltamethrin (CAS 52918-63-5; Sigma-Aldrich batch number: BCBS3148V, purity: 99.7\%) and cypermethrin (CAS 52315-07-8; Sigma-Aldrich batch number: BCBW1786, purity: 98.4\%) are type-II pyrethroid insecticides that mimic 
natural pyrethrins by interfering with sodium ion channels of nerve cells. Deltamethrin and cypermethrin are applied to numerous agricultural crops, such as corn, cotton, and rice, and play a vital role in integrated pest management strategies to reduce vector populations. Although estimated use records of each pesticide are scarce for African countries, some records are listed by the Pesticide Action Network Africa (2020). Moreover, previous research has reported human exposure to each pesticide, and has found residues of each in the air, water, soil, and produce of African countries (Ntow et al. 2006; Aktar et al. 2009; Kosikowska and Biziuk 2010; Donald et al. 2016).

\section{Study organisms}

We obtained 50 infected Biomphalaria glabrata snails on 11 September 2018 that had been exposed to $S$. mansoni (NMRI strain) on 5 September 2018 from the National Institute of Allergy and Infectious Disease Schistosomiasis Resource Center of the Biomedical Research Institute (Rockville, MD, USA). Snails were held individually in 200-mL containers filled with $200 \mathrm{~mL}$ high-hardness COMBO (HH COMBO; Oasis) water (Baer et al. 1999) and fed ad libitum a ration of ground fish flakes (Tetramin ${ }^{\circledR}$ ) and spirulina (NOW FOODS ${ }^{\circledR}$ ) suspended in agar (Fisher BioReagents ${ }^{\circledR}$ ). Snails were held under laboratory conditions (25.5 ${ }^{\circ} \mathrm{C}, 12: 12$-h light:dark), and full water exchanges were conducted biweekly.

\section{Time-to-death assay design}

We examined the effects of the 4 pesticides on the survival and behavior of free-swimming cercariae of $S$. mansoni using a 24-h time-to-death assay on 19 November 2018. We conducted the time-to-death assay using 24-well tissue culture plates (Falcon ${ }^{\circledR} \# 353047$; Corning). We tested 5 concentrations of each insecticide for a total of 20 pesticide treatments. To these treatments, we added a water control and an ethanol vehicle control. A vehicle control was included in the experimental design because pyrethroid insecticides are insoluble in water. We included 2 replicates of each control treatment and 1 replicate of each pesticide treatment on each 24 -well plate and used 5 plates for a total of 120 wells.

To obtain Schistosoma cercariae, 8 infected snails were transferred to $50-\mathrm{mL}$ glass beakers filled with $15 \mathrm{~mL}$ of oxygenated $\mathrm{HH}$ COMBO water and were held under direct artificial light for $1.5 \mathrm{~h}$. Snails were then returned to their respective husbandry containers, the $15-\mathrm{mL}$ HH COMBO solutions containing shed cercariae were homogenized, and we dispensed 250 $\mu \mathrm{L}$ of cercariae slurry to each well. On average, this resulted in $5.05 \pm 0.43$ (mean \pm 1 standard error [SE]) cercariae/well.

We created our pesticide treatments by first making stock solutions of each chemical. Organophosphate insecticides were dissolved directly in HH COMBO water $(5 \mathrm{mg} / \mathrm{mL})$, whereas pyrethroid insecticides were dissolved using ethanol ( $0.05 \mathrm{mg}$ active ingredient/ $\mathrm{mL}$ ). We then added an aliquot of each stock solution to $10 \mathrm{~mL}$ of $\mathrm{HH}$ COMBO water to create an intermediate solution for each targeted concentration (20 intermediate solutions). Prior to addition of stock solutions, we removed the same volume of HH COMBO water from the $10-\mathrm{mL}$ intermediate vial that we would be adding to correct for total volume. We added $100 \mu \mathrm{L}$ of each intermediate solution to their respective wells to obtain the nominal concentrations of 10, 30, 50, 70, and $100 \mu \mathrm{g} / \mathrm{L}$ for pyrethroids and 100, 200, 300, 
$400,500 \mathrm{mg} / \mathrm{L}$ for organophosphates. Although the chosen nominal pesticide concentrations fall above expected environmental concentrations (Table 1), they were selected following a series of pilot studies with the aim of causing increased cercariae mortality (see the Supplemental Data). The goal of our pilot studies was to identify concentrations for each insecticide class in which exposure caused a range of mortality. We initially employed 0.1 , $0.5,1.0,2.0$, and $10.0 \mu \mathrm{g}$ active ingredient/L for pyrethroids and $5,10,35,75$, and $100 \mathrm{mg}$ active ingredient/L for organophosphates. However, we did not observe significant death at these lower concentrations compared with the water control. Thus, we raised concentrations for both pesticide classes for the present experiment above the highest concentrations of the pilot studies. The ethanol vehicle control was created by adding $101 \mu \mathrm{L}$ of ethanol (95\%) to $9.899 \mathrm{~mL}$ of $\mathrm{HH}$ COMBO water to match the ethanol concentration in the highest volume of pyrethroid stock solution being transferred to the intermediate solution. To create our water controls, we instead added $100 \mu \mathrm{L}$ of HH COMBO water to each respective well. We then added $15 \mu \mathrm{L}$ Corning ${ }^{\text {TM }}$ Trypan blue dye (Cat. no. MT25900CI; Fisher Scientific) to each well for cercarial staining. We conducted a 24-h time-to-death assay to compare survival of cercariae exposed to Trypan blue stain with that of cercariae in water controls and found no effect of staining on survival $(p=0.44)$. Lastly, we added $135 \mu \mathrm{L}$ of HH COMBO water to each well to bring the total volume to $500 \mu \mathrm{L}$.

We assessed survival and activity of shed cercariae ( 1.5-h old) using a 24-h toxicity test conducted under laboratory conditions $\left(22^{\circ} \mathrm{C} ; 12: 12\right.$-h light:dark cycle). Because survival and infectivity have been reported up to $24 \mathrm{~h}$ postemergence (Purnell 1966), we observed cercariae every $2 \mathrm{~h}$ for the first $12 \mathrm{~h}$, and then every $6 \mathrm{~h}$ for the second $12 \mathrm{~h}$. To assess survival, we counted the number of unstained (alive) and stained (dead) individuals. We simultaneously assessed activity of alive, unstained cercariae by recording the number of active individuals; an individual was recorded as active if it was actively swimming, crawling, or moving vertically or horizontally in the water column. We did not conduct water exchanges or renew pesticide concentrations during the 24-h exposure period. After $24 \mathrm{~h}$, we added $20 \mu \mathrm{L}$ Lugol's iodine solution to each well to euthanize and stain surviving cercariae. Lugol's iodine solution was used to determine the total number of cercariae/well because we used a standardized volume of shed cercariae in favor of separating individuals to reduce handling time of cercariae.

\section{Statistical analysis}

To examine the direct toxic effects of the 4 insecticides on $S$. mansoni cercariae, we analyzed cercarial survival over time using Cox's proportional hazard models (Cox 1972). We first conducted an analysis comparing survival of cercariae exposed to the ethanol vehicle control and the water control to assess any effect of the vehicle. We did not find any difference between the 2 treatments ( $p=0.94$; Table 2). We thus pooled the ethanol vehicle and water controls for all subsequent survival analyses. We first used Cox's proportional hazards model to investigate the main effect of pesticide treatment to assess whether cercarial survival in a pesticide treatment differed from survival in the pooled controls. We then conducted 4 independent survival analyses, one for each insecticide, to examine the effect of concentration (continuous variable) on cercarial survival. The pooled control treatment served as a $0.0 \mu \mathrm{g} / \mathrm{L}$ concentration in each model. Following a significant effect of 
concentration, we then compared the survival of cercariae in each insecticide concentration (categorical variable) with the survival of cercariae in the pooled control treatment. We included "experimental well" as a random effect in each model. Cox's proportional hazards model were employed using RStudio Ver 1.1.453 (R Development Core Team 2016) and the survival and coxme packages. In addition, we used the drc package in RStudio to estimate the effective dose at 10, 50, and 90\% (ED10, ED50, and ED90) for pesticides that induced significant concentration effects on cercarial survival. We first used the $\mathrm{drm}$ function to examine the effect of $\log _{10}$-transformed methamidophos concentration $(+1)$ on the occurrence of cercarial death, and then backcalculated estimated effective doses $\left(10^{\mathrm{X}}-\right.$ $1)$.

To test whether cercarial activity over time was affected by insecticide exposure, we employed generalized linear mixed-effects models. We first examined whether activity over time differed between cercariae exposed to the water and to the ethanol vehicle controls. We examined whether the interactive effects of control treatment and time (independent variables) influenced the activity of cercariae, represented by the binomial response of the number of active and inactive cercariae within each experimental well. We found no difference in the activity of cercariae in the 2 control treatments $\left(\chi^{2}{ }_{(1)}=1.97, p=0.161\right)$, so we pooled the water and ethanol vehicle controls. We first investigated the overall effect of pesticide treatment and time (independent variables) on cercarial activity. For each insecticide, we then investigated the interactive effects of concentration (continuous) and time (independent variables) on cercarial activity. If we observed a significant effect of concentration, we then conducted a subsequent model that investigated the main and interactive effects of pesticide concentration (categorical) and time on the activity of cercariae and conducted Tukey's post hoc pairwise comparisons. We included "experimental well" as a random effect term within each model. Model analyses were conducted using RStudio and the car, Ime4, and multcomp packages.

\section{RESULTS}

\section{Time-to-death assays}

Cox's proportional hazard models revealed that survival of cercariae exposed to cypermethrin, deltamethrin, and dimethoate did not differ from cercarial survival in the pooled controls $(p \geq 0.31$; Table 2$)$. Survival of cercariae exposed to methamidophos was significantly higher than survival in the pooled controls $(p<0.001)$. Unsurprisingly, we found there was no effect of concentration on the survival of cercariae exposed to cypermethrin, deltamethrin, or dimethoate ( $p \geq 0.64$; Table 2 and Supplemental Data S1 Dataset). In contrast, we did find a significant effect of methamidophos concentration on cercarial survival $(b=-0.003, p=0.002)$. Exposure to $100,200,300$, and $400 \mathrm{mg} / \mathrm{L}$ methamidophos increased cercarial survival relative to the pooled controls ( $p \leq 0.031$; Figure 1 and Table 2). Survival of cercariae exposed to $500 \mathrm{mg} / \mathrm{L}$ methamidophos did not differ from survival of cercariae in the pooled controls $(p=0.12)$. After $24 \mathrm{~h}$ of exposure, survival of cercariae in the pooled control was $41.3 \%$ compared with more than $73 \%$ for cercariae exposed to any methamidophos concentration. 
To examine the toxicity of methamidophos to $S$. mansoni cercariae, we calculated the 24-h effective dose. The slope $(b ; p=0.4517)$ and the median lethal dose $(e ; p=0.4380)$ parameter estimates from the 2-parameter log-logistic model with fixed lower and upper limits were not different from 0. The estimated 24-h ED10, ED50, and ED90 values $( \pm \mathrm{SE})$ for methamidophos were $0.61( \pm 3.68), 7.06( \pm 13.75)$, and $9770.92 \mathrm{mg} / \mathrm{L}( \pm 628.13)$, respectively.

\section{Activity assay}

To examine the influence of insecticide exposure on cercarial activity, we used generalized linear mixed-effects models. Pesticide treatment $(p<0.001)$ and time $(p<0.001)$, but not their interaction $(p=0.185)$, affected cercarial survival. Cercarial activity was negatively associated with time across all pesticide treatments. Post hoc multiple comparison tests revealed that cercarial activity following methamidophos exposure was significantly reduced compared with all other treatments $(p<0.001)$. Cercarial activity did not differ between any other pesticide treatments and the pooled controls $(p \geq 0.679)$. Although we did not find an effect of concentration $(p \geq 0.149)$ or a concentration-by-time interaction $(p \geq 0.366)$ for dimethoate, cypermethrin, or deltamethrin, activity declined with time for all 3 insecticides $(p<0.001)$. For methamidophos, concentration $\left(\chi^{2}{ }_{(1)}=37.48, p<0.001\right)$ and time $\left(\chi^{2}(1)=\right.$ 46.40, $p<0.001)$, but not their interaction $\left(\chi^{2}(1)=0.534, p=0.4649\right)$, influenced cercarial activity (Figure 2 and Supplemental Data, S2 Dataset). Post hoc multiple comparison tests (Tukey) revealed that the mean activity of cercariae exposed to 300,400 , and $500 \mathrm{mg} / \mathrm{L}$ methamidophos was lower than the activity in the pooled controls ( $p \leq 0.047$; Figure 2A). Activity of cercariae exposed to 100 and $200 \mathrm{mg} / \mathrm{L}$ methamidophos did not differ from that in the pooled controls $(p \geq 0.076)$. Excluding the $0 \mathrm{mg} / \mathrm{L}$ control, activity of cercariae did not differ among methamidophos concentrations $(p \geq 0.071)$. Mean cercarial activity declined over time (Figure 2B).

\section{DISCUSSION}

In the present study, we sought to understand how free-swimming Schistosoma cercariae respond to 4 insecticides from 2 chemical classes commonly used in agricultural practices in developing regions endemic to schistosomiasis. We found no significant effect of exposure to cypermethrin, deltamethrin, and dimethoate on the survival and activity of $S$. mansoni cercariae over $24 \mathrm{~h}$. Surprisingly, exposure to methamidophos resulted in increased cercarial survival compared with the pooled control treatments. Moreover, the use of activity assays in combination with Trypan blue staining allowed us to observe that this increased survival appeared to be caused by the reduced activity of cercariae exposed to methamidophos.

Understanding the influence of common-use pesticides on waterborne pathogens is vital to protecting human health in developing regions. Our results suggest that cercariae are highly tolerant to the direct toxic effects of cypermethrin, deltamethrin, dimethoate, and methamidophos contamination. Given that the concentrations of insecticides reported in samples from developing regions all fall below concentrations used in the present study (Amoah et al. 2006; Aktar et al. 2009; Anderson et al. 2014; Diop et al. 2016; Donald et al. 2016), it is unlikely that Schistosoma cercariae suffer direct mortality from 
insecticide exposure. Previous research has also reported no influence of chlorpyrifos (organophosphate) or atrazine (triazine) exposure at environmentally relevant concentrations on S. mansoni survival over $12 \mathrm{~h}$ (Halstead et al. 2018). Although the indirect effects of agrochemicals have been shown to potentially propagate schistosomiasis by increasing intermediate snail host densities (Halstead et al. 2018; Becker et al. 2020), the results of the present study suggest that the direct toxicity of pesticides is not an apparent counteractive or mitigating factor for disease risk due to the substantial tolerance of cercarial life stage. Given the complex life cycle of $S$. mansoni, future studies should investigate the insecticide tolerance of other life stages such as miracidia, encysted individuals, and their intermediate snail hosts (Becker et al. 2020) to fully understand how pesticide exposure will influence disease transmission. Because it is unlikely that cercariae in surface waters of natural systems are exposed to only a single chemical compound at a time, future research should also investigate the effects of pesticide mixtures on cercarial longevity and infectivity (Halstead et al. 2014). Lastly, investigation into the direct toxic effects of other pesticide classes, such as organochlorines, will be useful because older, more toxic pesticides are still used in developing regions due to availability and low cost (Ecobichon 2001).

Exposure to pesticides can also cause sublethal changes in behavior and physiology that can alter metabolic processes and energy use. We observed decreased activity of $S$. mansoni cercariae exposed to methamidophos, which was likely caused by full or partial paralysis. The life span (24-48 h) of $S$. mansoni cercariae is dependent on finite glycogen and fat reserves, and we hypothesized that the paralyzed cercariae might have prolonged longevity because of lower rates of energy consumption (Krakower 1940; Ginetsinskaya 1968). Indeed, we observed reduced cercarial activity among individuals exposed to methamidophos relative to the activity of cercariae in all other treatments. Other pesticides and naturally occurring chemicals have also been reported to reduce mobility of nematodes and trematodes, including S. mansoni (Hara and Kaya 1983; Koprivnikar et al. 2006; Gao et al. 2019). The data suggest that the exposure to methamidophos caused a true paralytic effect through acetylcholinesterase inhibition in affected individuals, because past research has shown that certain cholinergic agents exert an inhibitory effect on muscular activity of $S$. mansoni and other parasites (Bueding 1962; Barker et al. 1966).

Although methamidophos-exposed cercariae lived longer than cercariae in the pooled controls, they were "functionally dead" because their immobility prevents them from searching for and infecting definitive hosts (Gao et al. 2019). Methamidophos-induced paralysis and increased survival were consistent results found in both our preliminary work (see the Supplemental Data) and the present study, which were conducted on cercariae from separate snails. Thus, these results suggest that $S$. mansoni responses to methamidophos are conserved across cercariae shed by different intermediate hosts. Therefore, it is possible that methamidophos-induced paralysis could reduce disease transmission and thus negative impacts on humans. In contrast, if exposure is short-lived, because of either environmental breakdown or clearance by flowing water, we may overestimate the acute toxicological effects of methamidophos on the reduction of disease transmission. Furthermore, it is possible that the continuous daily release of thousands of cercariae by infected snail hosts in natural systems (Combes et al. 1994) will minimize the influence of pesticide-induced cercarial paralysis on disease dynamics. Infection assays in the future should seek to 
confirm whether the cercarial paralysis observed in the present study provides protection to human hosts (Gao et al. 2019). Lastly, the methamidophos-induced paralysis may be strain-, species-, and life stage-specific, providing many questions for future researchers including the comparison of tolerance between laboratory-reared and field-collected Schistosoma cercariae, and whether tolerance varies among free-swimming cercariae or miracidia and encysted individuals. Future research that examines the complex relationship among trematode life stage, infected snail hosts, timing and frequency of pesticide exposure, and environmental conditions (e.g., flow, temperature) could reveal how each factor contributes to the transmission dynamics of schistosomiasis (sensu Halstead et al. 2018).

The combined use of Trypan blue staining and activity assays employed in the present study not only allowed us to discriminate whether cercariae were active versus inactive, but also whether they were paralyzed versus truly dead. This could have implications for the interpretation of previous toxicological assays of free-swimming trematode life stages that estimated lethal concentration values. For instance, previous research using activity to assign mortality to paralyzed cercariae (i.e., false positives) might underestimate the actual tolerance of trematodes and overestimate the toxicity of pesticides (Rohr et al. 2008).

Freshwater systems are increasingly threatened by numerous anthropogenic activities (Steinmann et al. 2006; Strayer and Dudgeon 2010; Stehle and Schulz 2015). Understanding the effects of contaminants on waterborne pathogens is of utmost importance in developing nations where water scarcity and increased agricultural activity might threaten human health (Rohr et al. 2019; Becker et al. 2020). Given the increased risk of agricultural runoff in these nations (Ippolito et al. 2015), it will be important for future studies to investigate the acute lethal and chronic sublethal effects of contaminants on aquatic pathogens. The combined use of activity assays with staining dye will better elucidate the lethal and sublethal effects of contaminants on waterborne pathogens, both improving toxicological estimates and more accurately predicting effects of pesticide exposure on disease dynamics.

\section{Supplementary Material}

Refer to Web version on PubMed Central for supplementary material.

\section{Acknowledgment-}

The authors thank C. Castro, K. Gionet, and A. Carey for their assistance with snail husbandry and experimental work, and S. Rumschlag for her assistance with statistical analyses and web tool calculations. The University of South Florida's Leadership Alliance Fellowship (to D.D. Davila) enabled this research. Biomphalaria glabrata snails were provided by the National Institute of Allergy and Infectious Diseases (NIAID) Schistosomiasis Resource Center of the Biomedical Research Institute (Rockville, MD) through National Institutes of Health-NIAID contract HHSN272201700014I for distribution through BEI Resources. Funds were provided by grants to J.R. Rohr from the National Science Foundation (EF-1241889, DEB-1518681, and IOS-1754868) and the National Institutes of Health (R01TW010286-01).

\section{Data Availability Statement-}

Data are included in the Supplemental Data as S1 Dataset and S2 Dataset. 


\section{REFERENCES}

Aktar MW, Paramasivam M, Sengupta D, Purkait S, Ganguly M, Banerjee S. 2009. Impact assessment of pesticide residues in fish of Ganga River around Kolkata in West Bengal. Environ Monit Assess 157:97-104. [PubMed: 18758975]

Alexandratos N, Bruinsma J. 2012. World agriculture towards 2030/2050: The 2012 revision. ESA Working paper. Food and Agriculture Organization of the United Nations, Rome, Italy.

Amoah P, Drechsel P, Abaidoo RC, Ntow WJ. 2006. Pesticide and pathogen contamination of vegetables in Ghana's urban markets. Arch Environ Contam Toxicol 50:1-6. [PubMed: 16328619]

Anderson KA, Seck D, Hobbie KA, Traore AN, McCartney MA, Ndaye A, Forsberg ND, Haigh TA, Sower GJ. 2014. Passive sampling devices enable capacity building and characterization of bioavailable pesticide along the Niger, Senegal and Bani Rivers of Africa. Philos Trans R Soc Lond B Biol Sci 369:20130110. [PubMed: 24535398]

Antwi FB, Reddy GVP. 2015. Toxicological effects of pyrethroids on non-target aquatic insects. Environ Toxicol Pharmacol 40:915-923. [PubMed: 26509732]

Baer KN, Ziegenfuss MC, Banks SD, Ling Z. 1999. Suitability of high-hardness COMBO medium for ecotoxicity testing using algae, daphnids, and fish. Bull Environ Contam Toxicol 63:289-296. [PubMed: 10475905]

Barker LR, Bueding E, Timms AR. 1966. Possible role of acetylcholine in Schistosoma mansoni. Br J Pharmacol Chemother 26:656-665. [PubMed: 4381202]

Baron JS, Poff NL, Angermeier PL, Dahm CN, Gleick PH, Hairston NG, Jackson RB, Johnston CA, Richter BD, Steinman AD. 2002. Meeting ecological and societal needs for freshwater. Ecol Appl 12:1247-1260.

Becker JM, Ganatra AA, Kandie F, Mühlbauer L, Ahlheim J, Brack W, Torto B, Agola EL, McOdimba F, Hollert H, Fillinger U, Liess M. 2020. Pesticide pollution in freshwater paves the way for schistosomiasis transmission. Sci Rep 10:1-13. [PubMed: 31913322]

Bernhardt ES, Rosi EJ, Gessner MO. 2017. Synthetic chemicals as agents of global change. Front Ecol Environ 15:84-90.

Bruckner DA, Vage M. 1974. The nervous system of larval Schistosoma mansoni as revealed by acetylcholinesterase staining. J Parasitol 60:437-446. [PubMed: 4833856]

Bueding E 1962. Effects of benzylic diamines on Schistosoma mansoni. Biochem Pharmacol 11:1728. [PubMed: 13874421]

Clements WH, Rohr JR. 2009. Community responses to contaminants: Using basic ecological principles to predict ecotoxicological effects. Environ Toxicol Chem 28:1789-1800. [PubMed: 19358627]

Combes C, Fournier A, Mone H, Theron A. 1994. Behaviors in trematode cercariae that enhance parasite transmission-Patterns and processes. Parasitology 109:S3-S13. [PubMed: 7854849]

Costanza R, de Groot R, Sutton P, van der Ploeg S, Anderson SJ, Kubiszewski I, Farber S, Turner RK. 2014. Changes in the global value of ecosystem services. Global Environ Chang 26:152-158.

Cox DR. 1972. Regression models and life-tables. J R Stat Soc B 34:187.

Diop A, Diop YM, Thiare DD, Cazier F, Sarr SO, Kasprowiak A, Landy D, Delattre F. 2016. Monitoring survey of the use patterns and pesticide residues on vegetables in the Niayes zone, Senegal. Chemosphere 144:1715-1721. [PubMed: 26519803]

Donald CE, Scott RP, Blaustein KL, Halbleib ML, Sarr M, Jepson PC, Anderson KA. 2016. Silicone wristbands detect individuals' pesticide exposures in West Africa. R Soc Open Sci 3:160433. [PubMed: 27853621]

Ecobichon DJ. 2001. Pesticide use in developing countries. Toxicology 160:27-33. [PubMed: 11246121]

Fenwick A 2012. The global burden of neglected tropical diseases. Public Health 126:233-236. [PubMed: 22325616]

Fleeger JW, Carman KR, Nisbet RM. 2003. Indirect effects of contaminants in aquatic ecosystems. Sci Total Environ 317:207-233. [PubMed: 14630423] 
Gao J, Yang N, Lewis FA, Yau P, Collins JJ, Sweedler JV, Newmark PA. 2019. A rotifer-derived paralytic compound prevents transmission of schistosomiasis to a mammalian host. PLoS Biol 17:e3000485. [PubMed: 31622335]

Ginetsinskaya T 1968. Trematodes, Their Life-Cycles, Biology and Evolution. Amerind, New Delhi, India.

Halstead NT, Hoover CM, Arakala A, Civitello DJ, De Leo GA, Gambhir M, Johnson SA, Jouanard N, Loerns KA, McMahon TA, Ndione RA, Nguyen K, Raffel TR, Remais JV, Riveau G, Sokolow SH, Rohr JR. 2018. Agrochemicals increase risk of human schistosomiasis by supporting higher densities of intermediate hosts. Nat Commun 9:837. [PubMed: 29483531]

Halstead NT, McMahon TA, Johnson SA, Raffel TR, Romansic JM, Crumrine PW, Rohr JR. 2014. Community ecology theory predicts the effects of agrochemical mixtures on aquatic biodiversity and ecosystem properties. Ecol Lett 17:932-941. [PubMed: 24811760]

Hara AH, Kaya HK. 1983. Toxicity of selected organophosphate and carbamate pesticides to infective juveniles of the entomogenous nematode Neoaplectana carpocapsae (Rhabditida, Steinernematidae). Environ Entomol 12:496-501.

Hua J, Buss N, Kim J, Orlofske SA, Hoverman JT. 2016. Population-specific toxicity of six insecticides to the trematode Echinoparyphium sp. Parasitology 143:542-550. [PubMed: 26928351]

Ippolito A, Kattwinkel M, Rasmussen JJ, Schafer RB, Fornaroli R, Liess M. 2015. Modeling global distribution of agricultural insecticides in surface waters. Environ Pollut 198:54-60. [PubMed: 25555206]

Jepson PC, Guzy M, Blaustein K, Sow M, Sarr M, Mineau P, Kegley S. 2014. Measuring pesticide ecological and health risks in West African agriculture to establish an enabling environment for sustainable intensification. Philos Trans R Soc Lond B Biol Sci 369:20130491. [PubMed: 24535399]

Kohler HR, Triebskorn R. 2013. Wildlife ecotoxicology of pesticides: Can we track effects to the population level and beyond? Science 341:759-765. [PubMed: 23950533]

Koprivnikar J, Forbes MR, Baker RL. 2006. Effects of atrazine on cercarial longevity, activity, and infectivity. J Parasitol 92:306-311. [PubMed: 16729687]

Kosikowska M, Biziuk M. 2010. Review of the determination of pesticide residues in ambient air. Trac-Trend Anal Chem 29:1064-1072.

Krakower CA. 1940. Some observations of the effects of physical and chemical agents on the cercariae of Schistosoma mansoni. Puerto Rico J Public Health Trop Med 16:26-44.

Lambin EF, Geist HJ, Lepers E. 2003. Dynamics of land-use and land-cover change in tropical regions. Annu Rev Environ Resour 28:205-241.

Lapworth DJ, Nkhuwa DCW, Okotto-Okotto J, Pedley S, Stuart ME, Tijani MN, Wright J. 2017. Urban groundwater quality in sub-Saharan Africa: Current status and implications for water security and public health. Hydrogeol J 25:1093-1116. [PubMed: 32055234]

Malaj E, von der Ohe PC, Grote M, Kuhne R, Mondy CP, Usseglio-Polatera P, Brack W, Schafer RB. 2014. Organic chemicals jeopardize the health of freshwater ecosystems on the continental scale. Proc Natl Acad Sci U S A 111:9549-9554. [PubMed: 24979762]

McMahon TA, Rohr JR. 2014. Trypan blue dye is an effective and inexpensive way to determine the viability of Batrachochytrium dendrobatidis zoospores. Ecohealth 11:164-167. [PubMed: 24519684]

Monte TCD, Garcia J, Gentile R, de Vasconcellos MC, Souza J, Braga BV, Maldonado A. 2016. In vivo and in vitro effects of the herbicide Roundup ${ }^{\circledR}$ on developmental stages of the trematode Echinostoma paraensei. Exp Parasitol 169:43-50. [PubMed: 27373431]

National Library of Medicine. 2019. Hazardous Substances Data Bank. Bethesday, MD, USA. [cited 2019 May]. Available from: https://toxnet.nlm.nih.gov/cgi-bin/sis/htmlgen?HSDB

Ntow WJ, Gijzen HJ, Kelderman P, Drechsel P. 2006. Farmer perceptions and pesticide use practices in vegetable production in Ghana. Pestic Manage Sci 62:356-365.

Olivier LJ. 1966. Infectivity of Schistosoma mansoni cercariae. Am J Trop Med Hyg 15:882-885. [PubMed: 5959101] 
Patz JA, Daszak P, Tabor GM, Aguirre AA, Pearl M, Epstein J, Wolfe ND, Kilpatrick AM, Foufopoulos J, Molyneux D, Bradley DJ, Working Group on Land Use C, Disease E. 2004. Unhealthy landscapes: Policy recommendations on land use change and infectious disease emergence. Environ Health Perspect 112:1092-1098. [PubMed: 15238283]

Patz JA, Graczyk TK, Geller N, Vittor AY. 2000. Effects of environmental change on emerging parasitic diseases. Int J Parasitol 30:1395-1405. [PubMed: 11113264]

Pesticide Action Network Africa. 2020. Pesticide Action Network Database. Dakar, Senegal. [cited 2019 May]. Available from: http://www.pan-afrique.org/departen.php

Pesticide Action Network, North America. 2019. PAN Pesticide Database. Berkeley, CA, USA. [cited 2019 May]. Available from: http://www.pesticideinfo.org/

Pietrock M, Marcogliese DJ. 2003. Free-living endohelminth stages: At the mercy of environmental conditions. Trends Parasitol 19:293-299. [PubMed: 12855379]

Purnell RE. 1966. Host-parasite relationships in schistosomiasis. 3. The effect of temperature on the survival of Schistosoma mansoni miracidia and on the survival and infectivity of Schistosoma mansoni cercariae. Ann Trop Med Parasitol 60:182-186. [PubMed: 5962470]

R Development Core Team. 2016. RStudio: Integrated Development Environment for R. Boston, MA, USA. [cited 2019 May]. Available from: http://www.rstudio.com/

Raffel TR, Sheingold JL, Rohr JR. 2009. Lack of pesticide toxicity to Echinostoma trivolvis eggs and miracidia. J Parasitol 95:1548-1551. [PubMed: 19463041]

Reddy A, Ponder EL, Fried B. 2004. Effects of copper sulfate toxicity on cercariae and metacercariae of Echinostoma caproni and Echinostoma trivolvis and on the survival of Biomphalaria glabrata snails. J Parasitol 90:1332-1337. [PubMed: 15715224]

Relyea R, Hoverman J. 2006. Assessing the ecology in ecotoxicology: A review and synthesis in freshwater systems. Ecol Lett 9:1157-1171. [PubMed: 16972879]

Rizak S, Hrudey SE. 2008. Drinking-water safety—Challenges for community-managed systems. J Water Health 6:33-41. [PubMed: 18401127]

Rohr JR, Barrett CB, Civitello DJ, Craft ME, Delius B, DeLeo GA, Hudson PJ, Jouanard N, Nguyen KH, Ostfeld RS. 2019. Emerging human infectious diseases and the links to global food production. Nature Sustainability 2:445.

Rohr JR, Kerby JL, Sih A. 2006. Community ecology as a framework for predicting contaminant effects. Trends Ecol Evol 21:606-613. [PubMed: 16843566]

Rohr JR, Raffel TR, Sessions SK, Hudson PJ. 2008. Understanding the net effects of pesticides on amphibian trematode infections. Ecol Appl 18:1743-1753. [PubMed: 18839768]

Rumschlag SL, Bessler SM, Rohr JR. 2019. Evaluating improvements to exposure estimates from fate and transport models by incorporating environmental sampling effort and contaminant use. Water Res 156:372-382. [PubMed: 30933695]

Salvador-Recatala V, Greenberg RM. 2012. Calcium channels of schistosomes: Unresolved questions and unexpected answers. Wiley Interdiscip Rev Membr Transp Signal 1:85-93. [PubMed: 22347719]

Sanchez-Bayo F 2012. Insecticides mode of action in relation to their toxicity to non-target organisms. J Environ Anal Toxicol S4:0002.

Sokolow SH, Jones IJ, Jocque M, La D, Cords O, Knight A, Lund A, Wood CL, Lafferty KD, Hoover CM, Collender PA, Remais JV, Lopez-Carr D, Fisk J, Kuris AM, De Leo GA. 2017. Nearly 400 million people are at higher risk of schistosomiasis because dams blockthe migration of snail-eating river prawns. Philos Trans R Soc Lond B Biol Sci 372:20160127. [PubMed: 28438916]

Southgate VR. 1997. Schistosomiasis in the Senegal river basin: Before and after the construction of the dams at Diama, Senegal and Manantali, Mali and future prospects. J Helminthol 71:125-132. [PubMed: 9192711]

Stehle S, Schulz R. 2015. Agricultural insecticides threaten surface waters at the global scale. Proc Natl Acad Sci U S A 112:5750-5755. [PubMed: 25870271]

Steinmann P, Keiser J, Bos R, Tanner M, Utzinger J. 2006. Schistosomiasis and water resources development: Systematic review, meta-analysis, and estimates of people at risk. Lancet Infect Dis 6:411-425. [PubMed: 16790382] 
Stensgaard AS, Utzinger J, Vounatsou P, Hurlimann E, Schur N, Saarnak CFL, Simoonga C, Mubita P, Kabatereine NB, Tchuente LAT, Rahbek C, Kristensen TK. 2013. Large-scale determinants of intestinal schistosomiasis and intermediate host snail distribution across Africa: Does climate matter? Acta Trop 128:378-390. [PubMed: 22142789]

Strayer DL, Dudgeon D. 2010. Freshwater biodiversity conservation: Recent progress and future challenges. J N Am Benthol Soc 29:344-358.

Strober W 2001. Trypan blue exclusion test of cell viability. Curr Protoc Immunol Appendix 3:Appendix 3B. 10.1002/0471142735.ima03bs21

Tilman D, Fargione J, Wolff B, D'Antonio C, Dobson A, Howarth R, Schindler D, Schlesinger WH, Simberloff D, Swackhamer D. 2001. Forecasting agriculturally driven global environmental change. Science 292:281-284. [PubMed: 11303102]

University of Hertfordshire. 2020. Pesticide Properties DataBase. Hertfordshire, UK. [cited 2019 May]. Available from: https://sitem.herts.ac.uk/aeru/ppdb/en/

Vorosmarty CJ, McIntyre PB, Gessner MO, Dudgeon D, Prusevich A, Green P, Glidden S, Bunn SE, Sullivan CA, Liermann CR, Davies PM. 2010. Global threats to human water security and river biodiversity. Nature 467:555-561. [PubMed: 20882010]

World Health Organization. 2010. Working to overcome the global impact of neglected tropical diseases: First WHO report on neglected tropical diseases. Geneva, Switzerland.

Williamson S, Ball A, Pretty J. 2008. Trends in pesticide use and drivers for safer pest management in four African countries. Crop Protection 27:1327-1334. 


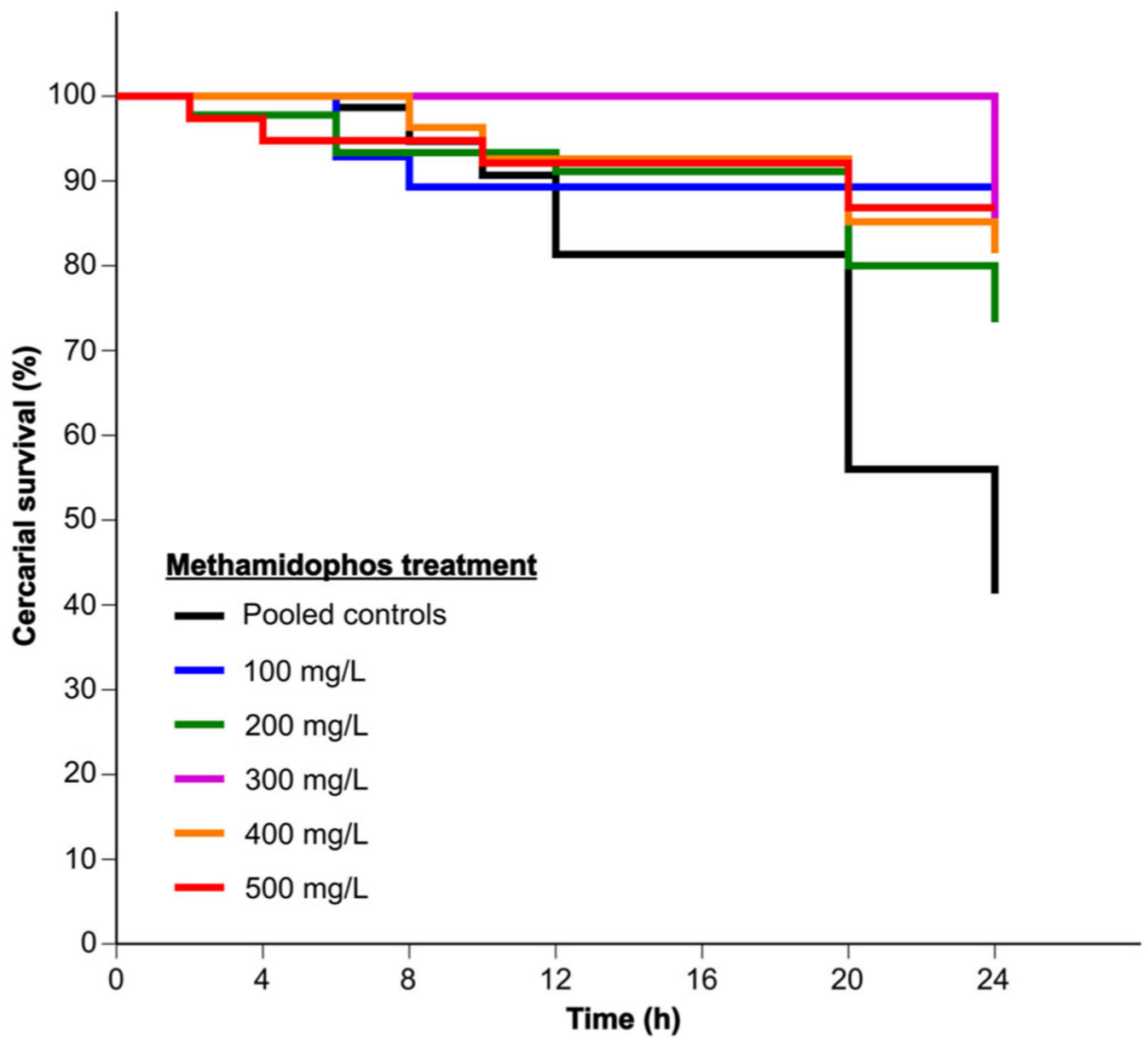

FIGURE 1:

Survival of Schistosoma mansoni cercariae following exposure to one of 6 methamidophos concentrations. Cercariae were exposed to $0,100,200,300,400$, or $500 \mathrm{mg} / \mathrm{L}$ methamidophos for $24 \mathrm{~h}$ using a time-to-death assay. The pooled control treatment represents the combined survival of cercariae in the water and vehicle control treatments. 
(A)

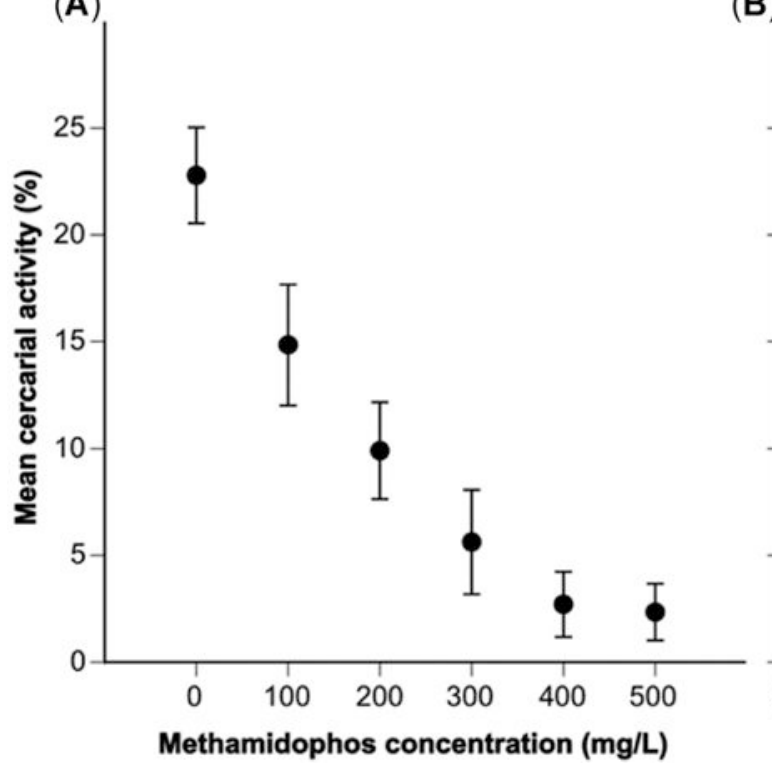

(B)

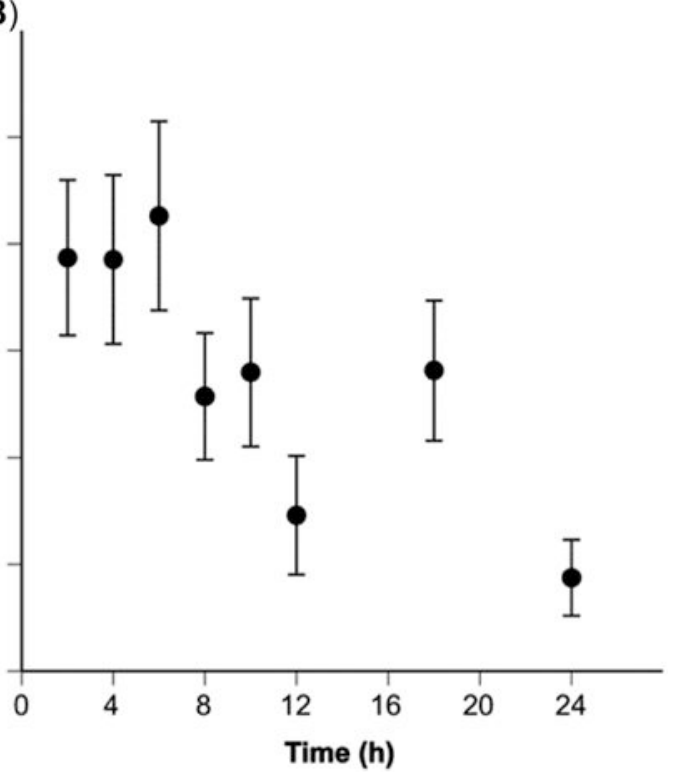

FIGURE 2:

Mean cercarial activity (\%) of Schistosoma mansoni following exposure to one of 6 methamidophos concentrations. We recorded the number of cercariae active over $24 \mathrm{~h}$ following exposure to $0,100,200,300,400$, or $500 \mathrm{mg} / \mathrm{L}$ methamidophos. We calculated cercarial activity (\%) by dividing the number of trematodes observed moving by the total number of individuals in the well. We observed the main effect of methamidophos concentration (A) and time (B) on cercarial activity. Data points represents overall treatment mean values \pm 1 standard error. 
TABLE 1:

Peak estimated environmental concentrations (EECs) for each insecticide ${ }^{a}$

\begin{tabular}{lccc}
\hline Pesticide & Crop & Water body & Peak EEC $(\mathbf{p p b} ; \boldsymbol{\mu g} / \mathbf{L})$ \\
\hline Methamidophos & Potato & Pond & 6.05 \\
& & Reservoir & 13.9 \\
Dimethoate & \multirow{2}{*}{ Corn } & Pond & 8.17 \\
& & Reservoir & 19.2 \\
Cypermethrin & \multirow{2}{*}{ Cotton } & Pond & 0.859 \\
& & Reservoir & 2.03 \\
Deltamethrin & \multirow{2}{*}{ Corn } & Pond & 0.0036 \\
& & Reservoir & 0.0086 \\
\hline
\end{tabular}

${ }^{a}$ We used the US Environmental Protection Agency Pesticide in Water Calculator (PWC; Ver 1.52) to calculate EEC values for pond and reservoir surface waters. Following previously described methods (Rumschlag et al. 2019), we extracted pesticide parameters from the Pesticide Properties DataBase of the University of Hertfordshire (2020), the Pesticide Action Network, North America Pesticide Database (2019), and the Hazardous Substances Data Bank (National Library of Medicine 2019). We then selected the maximum EEC value generated by the PWC calculator. 
TABLE 2:

Results of Cox's proportional hazard models

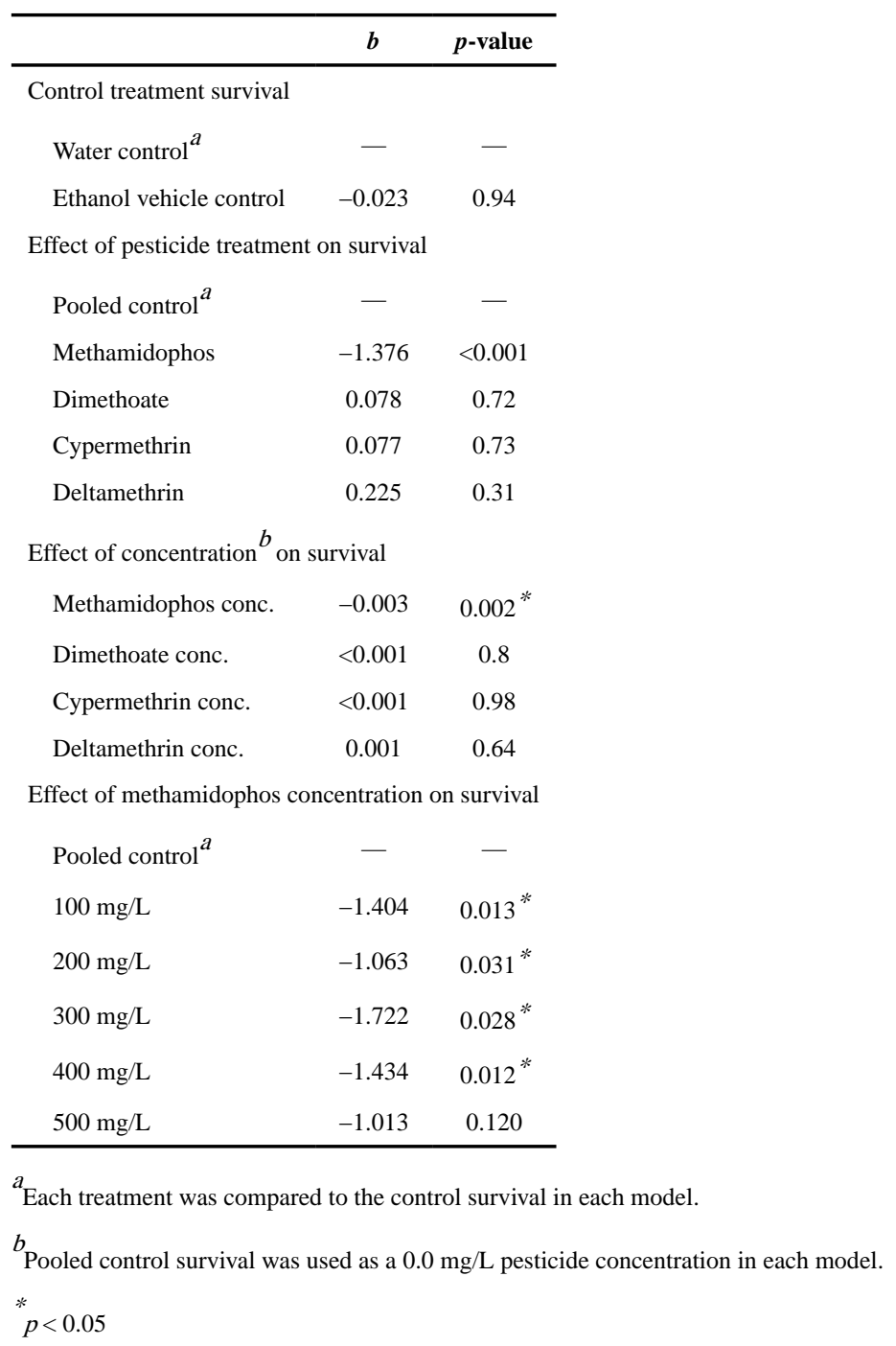

Environ Toxicol Chem. Author manuscript; available in PMC 2021 November 05. 